\title{
Hospitalization due to adverse drug reactions and drug interactions before and after HAART
}

\author{
Michelle M Foisy PharmD ${ }^{1}$, Kevin Gough MD FRCPC ${ }^{2}$, Corinna M Quan MD FRCPC ${ }^{3}$, \\ Kevin Harris MD CCFP ${ }^{4}$, Dominique Ibanez $\mathrm{MSC}^{5}$, Anne Phillips MD FRCPC ${ }^{6}$
}

MM Foisy, K Gough, CM Quan, K Harris, D Ibanez, A Phillips. Hospitalization due to adverse drug reactions and drug interactions before and after HAART. Can J Infect Dis 2000;11(4):193-201.

OBJECTIVE: To characterize and compare the rates of adverse drug reactions (ADRs) and interactions on admission in two, one-year periods: pre-highly active antiretroviral therapy (HAART) (phase 1) and post-HAART (phase 2).

DESIGN: Retrospective chart review.

SETTING: University-affiliated tertiary care centre.

POPULATION STUDIED: HIV-positive patients admitted to hospital.

MAIN RESULTS: In phase 1, 436 of 517 admissions, and, in phase 2, 323 of 350 admissions were analyzed. Over $92 \%$ of patients were male, with a mean age of 38 years. Significant differences $(\mathrm{P}<0.05)$ in the mean length of stay $(12.08$ versus 10.02 days), the CD4 counts (99.25 versus 129.45 ) and the number of concurrent diseases (4.20 versus 3.63 ) were found between phase 1 and 2, respectively. The mean number of medications taken (5.52 versus 5.94) and the rates of hospitalization with ADRs (20.4\% versus $21.4 \%$ ) or interactions (2.5\% versus $2.16 \%$ ) were similar between the two phases. Antiretrovirals were more common in ADR admissions post-HAART (21.3\% versus $36.2 \%$ ), while antiparasitics, psychotherapeutics and antineoplastics were more common pre-HAART. Other classes of drugs involved in both phases were sulphonamides, narcotics, ganciclovir, foscarnet, antimycobacterials and antifungals. ADR causality was possible or probable in more than $80 \%$ of cases. Over $60 \%$ of ADRs were grades 3 to 4 , and about $85 \%$ were either the main or contributing reason for admission. About $65 \%$ of patients had at least partial recovery at the time of discharge. In phases 1 and $2,8.9 \%$ and $2.9 \%$ of admissions, respectively, with ADRs were fatal.

CONCLUSIONS: Although hospitalizations with ADRs and interactions were similar in both phases, HAART therapy has had a significant impact on the incidence and nature of ADRs at St Michael's Hospital, Wellesley Central Site, Toronto, Ontario.

Key Words: Adverse drug reactions; Drug interactions; Hospitalization; Human immunodeficiency virus

\section{Hospitalisations liées à des réactions médicamenteuses indésirables et à des interactions médicamenteuses avant et après un HAART}

OBJECTIF : Caractériser et comparer les taux de réactions médicamenteuses indésirables (RMI) et des interactions médicamenteuses à l'admission des patients au cours de deux périodes d'un an : la phase 1 ou pré-HAART (highly active antiretroviral therapy) ou pré-traitement antirétroviral hautement actif et la phase 2 ou post-HAART.

MODÈLE : Examen rétrospectif des dossiers médicaux.

voir page suivante

\footnotetext{
${ }^{1}$ St Michael's Hospital, The Wellesley Health Centre and University of Toronto; ${ }^{2}$ Infectious Diseases and HIV, Inner City Health Program, St Michael's Hospital and University of Toronto; ${ }^{3}$ Infectious Diseases, St Michael's Hospital, Wellesley Central Site; ${ }^{4}$ Emergency Department, St Michael's Hospital, Wellesley Central Site, Toronto; ${ }^{5}$ Ibanez Consulting, Etobicoke; ${ }^{6}$ HIV Program, St Michael's Hospital and University of Toronto, Toronto, Ontario

Correspondence and reprints: Dr Kevin Gough, 160 Wellesley Street East, Room 114C, Jones Building, Toronto, Ontario M4Y 1 J3.

Telephone 416-926-5053 ext 7728, fax 416-926-5000, e-mail kgough@twh.on.ca

Received for publication April 29, 1999. Accepted July 30, 1999
} 
CONTEXTE : Centre de soins tertiaires affilié à une université.

POPULATION ÉTUDIÉE : Patients porteurs du VIH et hospitalisés.

PRINCIPAUX RÉSULTATS : Dans la phase 1, 436 sur 517 hospitalisations, et, dans la phase 2, 323 sur 350 hospitalisations ont été analysées. Plus de $92 \%$ des patients étaient des hommes, âgés en moyenne de 38 ans. Des différences significatives $(\mathrm{p}<0,05)$ dans la durée moyenne de l'hospitalisation (12,08 par rapport à 10,02 jours), du nombre des CD4 $(99,25$ par rapport à 129,45$)$ et dans le nombre de maladies concomitantes $(4,20$ par rapport à 3,63$)$ ont été révélées, respectivement entre la phase 1 et la phase 2 . Le nombre moyen de médicaments pris (5,52 par rapport à $5,94)$ et les taux d'hospitalisation liées à des RMI $(20,4 \%$ par rapport à $21,4 \%)$ ou des interactions $(2,5 \%$ par rapport à $2,16 \%$ ) étaient similaires entre les deux phases. Les antirétroviraux étaient plus courants dans le cas d'hospitalisations dues à des RMI en post-HAART (21,3\% par rapport à 36,2\%), tandis que les agents antiparasitaires, psychotropes et antinéoplasiques étaient plus courants en pré-HAART. D'autres classes de médicaments impliquées dans les deux phases étaient les sulfamides, les narcotiques, le ganciclovir, le foscarnet, les antimycobactériens et les antifongiques. Dans plus de $80 \%$ des cas, il était possible ou probable d'imputer ces hospitalisations à des RMI. Plus de $60 \%$ des RMI étaient cotées 3 ou 4, et environ $85 \%$ constituaient la principale raison de l'hospitalisation ou y avaient contribué. Environ $65 \%$ des patients étaient au moins partiellement rétablis au moment de leur congé. Dans les phases 1 et 2 , respectivement $8,9 \%$ et $2,9 \%$ des hospitalisations liées à des RMI avaient été mortelles.

CONCLUSIONS : Bien que les taux d'hospitalisations liées à des RMI et à des interactions médicamenteuses aient été similaires dans les deux phases, un HAART a eu un impact significatif sur l'incidence et la nature des RMI au St Michael's Hospital, Wellesley Central Site, à Toronto, en Ontario.

$\mathrm{T}$ he nucleoside reverse transcriptase inhibitor (NRTI) zidovudine was the first antiretroviral to be released in the late 1980s. Since that time, four other NRTIs have been marketed, and two new classes of antiretrovirals have been added to the armamentarium of therapies - the protease inhibitors (PIs) and the non-nucleoside reverse transcriptase inhibitors (NNRTIS). Over a dozen antiretrovirals are widely used in various combinations to treat human immunodeficiency virus (HIV) infection. Similarly, treatment options for opportunistic infections have also expanded in the past decade. For instance, clinicians now have the choice of at least five antifungals and therapies for Pneumocystis carinii pneumonia, three agents for cytomegalovirus disease and several new agents for Mycobacterium avium complex infection.

Although short term studies have demonstrated that the new antiretroviral combinations have been highly effective in decreasing viral load, in prolonging progression to the development of acquired immunodeficiency syndrome (AIDS) and in prolonging life in relatively advanced stage patients, these therapies are still fraught with toxicities (1-3). For example, zidovudine has been associated with severe anemia and neutropenia (4), didanosine (Videx, Bristol Laboratories of Canada, Montreal, Quebec) can cause life-threatening pancreatitis (5), and indinavir (Crixivan, Merck Sharp \& Dohme Canada, Kirkland, Quebec) has been associated with nephrolithiasis (6).

To compound the issue further, the potential for drug interactions has escalated with the advent of highly active antiretroviral therapy (HAART). Because NNRTIs and PIs are substrates of the hepatic cytochrome p450 (CYP450) enzyme system, drugs that are inhibitors or inducers of these enzymes have the potential to affect the antiviral concentrations. Furthermore, PIs are all inhibitors of various CYP450 isoenzymes, and the NNRTIs delavirdine and nevirapine/efavirenz are CYP450 inhibitors and inducers, respectively. There are well over 200 known and speculated drug interactions with these two classes of drugs combined $(7,8)$.

As the complexity and treatment options for HIV disease and related opportunistic infections increase, HIV-positive patients are at risk of experiencing significant drug-related mor- bidity and possibly even mortality. In the current era of fiscal restraint, when reductions in both the number of hospital admissions and the duration of hospitalization are desirable, adverse drug reactions (ADRs) to medications may contribute significantly to increasing hospitalization, morbidity and mortality. Therefore, it is necessary to investigate the impact of HIV therapies on hospitalization rates and patient outcomes.

The study objectives were several-fold. Admissions with ADRs and/or drug interactions in HIV patients were characterized. Patient demographics, the classes of medications contributing to ADRs and interactions, the nature of ADRs or interactions, causality, intensity, contribution to overall admission, outcomes, and length of admission were compared pre- and post-HAART. The overall contribution of antiretroviral ADRs and interactions to hospitalization pre- and post-HAART was characterized. Lastly, general medication use patterns preand post-HAART were analyzed.

\section{PATIENTS AND METHODS}

Design and setting: A retrospective chart review was conducted at St Michael's Hospital, Wellesley-Central Site, Toronto, Ontario, which is a university-affiliated tertiary care centre. Data were collected by a pharmacist and several infectious disease physicians with expertise in HIV. These practitioners were also involved in the care of the admitted patients during the periods under study. Two time periods were compared: phase 1 - pre-HAART (April 1, 1995 to March 31, 1996) and phase 2 - post-HAART (August 1, 1996 to August 31, 1997). The time period for phase 2 was selected given that ritonavir (Norvir, Abbott Laboratories Limited, Saint-Laurent, Quebec), saquinavir (Invirase, Hoffman-La Roche Limited, Mississauga, Ontario) and indinavir were all marketed in Canada by August 1996. Patients were identified through the hospital database in medical records. Approval from the institution's Research Ethics Board was obtained.

Population studied: Data were collected from the charts of all patients with a diagnosis of HIV infection at the time of admission. The patients were screened for ADRs and significant drug interactions present at the time of admission. 
TABLE 1

Patient characteristics at time of admission

\begin{tabular}{lccc}
\hline & Phase 1 (Pre-HAART) & Phase 2 (Post-HAART) & P \\
\hline Total number of admissions & $\mathrm{n}=436$ & $\mathrm{n}=323$ & 0.885 \\
Age (years) & $38.65 \pm 7.38(\mathrm{n}=434)^{*}$ & $38.56 \pm 8.60(\mathrm{n}=322)^{*}$ & 0.354 \\
Male $(\%)$ & 94.2 & 92.6 & $0.0118^{+}$ \\
CD4 count (cells $\left./ \mathrm{mm}^{3}\right)$ & $99.25 \pm 142.13(\mathrm{n}=384)^{*}$ & $129.45 \pm 161.25(\mathrm{n}=288)^{*}$ & $0.0008^{+}$ \\
Number of concurrent diseases & $4.20 \pm 2.33$ & $3.63 \pm 2.25$ & 0.156 \\
Number of medications & $5.52 \pm 3.71$ & $5.94 \pm 4.27$ & $0.0314^{+}$ \\
Length of stay (days) & $12.08 \pm 13.28$ & $10.02 \pm 12.69$ & \\
\hline
\end{tabular}

${ }^{*}$ Data available; ${ }^{\dagger} P<0.05$. HAART Highly active antiretroviral therapy

Definitions: Hospitalization was defined as admission to the hospital for at least $24 \mathrm{~h}$. ADRs were defined as any undesirable clinical response that may be due to any drug(s) administered to the patient (9). The following descriptions for ADRs were used:

Causality: Causality of ADRs was based on a previously published scale by Bergman and Wiholm (10) and adaptation by Grymonpre et al (11). The probability was defined as definite, probable, possible, conditional, doubtful or unknown. These terms are similar to those used in the Health Canada ADR reporting system (12).

Intensity: The reaction intensity was classified as grade 1 (mild), grade 2 (moderate), grade 3 (severe), grade 4 (very severe) or unknown (13).

Contribution to admission: The overall relation of each ADR to hospitalization was classified as main reason, contributing reason, unrelated or unknown.

Patient outcome: At the time of discharge, the patient outcome was classified as recovered, recovered with residual effect, not yet recovered, fatal or unknown.

A drug interaction was defined as an actual or potential ADR caused by the concurrent administration of two or more drugs. Drug interactions were identified by the use of several databases, based on Drug Interaction Facts (14), Drug Interaction Analyses and Management (15), and several review articles summarizing drug interactions in HIV treatment $(7,8)$.

Data analysis - Statistical analysis: Data entry and analysis were performed using the computer software program Statistical Analysis System (SAS Institute Inc, Cary, North Carolina). The ${ }^{2}$ test was used to compare the distribution of medication classes taken during the two phases, the drug classes involved in the ADRs, the organ systems affected, causality, severity of reaction, the contribution to admission and the outcome at discharge. The Student's $t$ - test was employed to compare the length of hospitalization between the two groups.

\section{RESULTS}

Demographics and hospitalization duration: In total, there were 476 patients studied, which accounted for 759 admissions (265 patients with admissions in phase 1,187 with admissions in phase 2 and 24 with admissions in both phases). In the pre-HAART period (phase 1), 436 of 517 admissions were reviewed. In the post-HAART period (phase 2), 323 of 350

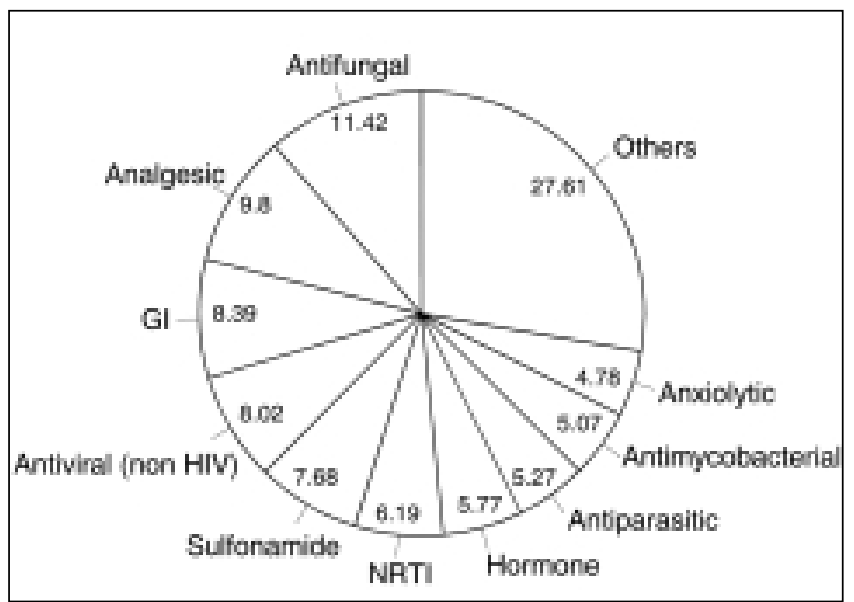

Figure 1) Drug classes taken before highly active antiretroviral therapy (phase 1). The percentage breakdown of medication classes is equal to the total number of drugs taken per class divided by the total number of drugs taken in all classes. GI Gastrointestinal; NRTI Nucleoside reverse transcriptase inhibitor

admissions were reviewed. If charts were repeatedly unavailable from medical records, pertinent admissions were excluded from the study. Demographic data on admission are summarized in Table 1. There were no differences regarding sex, mean age and the number of medications on admission. Patients had significantly higher CD4 counts, fewer concomitant diseases and decreased duration of hospitalization post-HAART than pre-HAART.

Drug use patterns: Figures 1 and 2 show the top 10 medication classes prescribed in each phase. There was a significant change in the distribution of medications used in the two phases $(\mathrm{P}=0.001)$. Of all medications prescribed, NRTIs and PIs accounted for $6.19 \%$ and $0.54 \%$ in phase 1 , and $17.55 \%$ and $7.97 \%$ in phase 2 , respectively. Overall, there were significantly more patients on antiretrovirals $(57.0 \%)$ in phase 2 than in phase 1 (26.4\%) ( $\mathrm{P}=0.001)$.

Admissions with ADRs: There were 89 admissions (a total of 97 ADRs) and 69 admissions (a total of 78 ADRs) with ADRs in phases 1 and 2, respectively. This accounted for $20.4 \%$ (89 of 436) of admissions in phase 1 and $21.4 \%$ (69 of 323) of admissions in phase $2(\mathrm{P}=0.750)$. More than one ADR was identified in a small portion of admissions in both phases (eight versus seven with two admissions and zero versus one with three admissions due to ADRs in phases 1 and 2, respectively). Table 2 compares patient characteristics on admission. In phase 2 , 


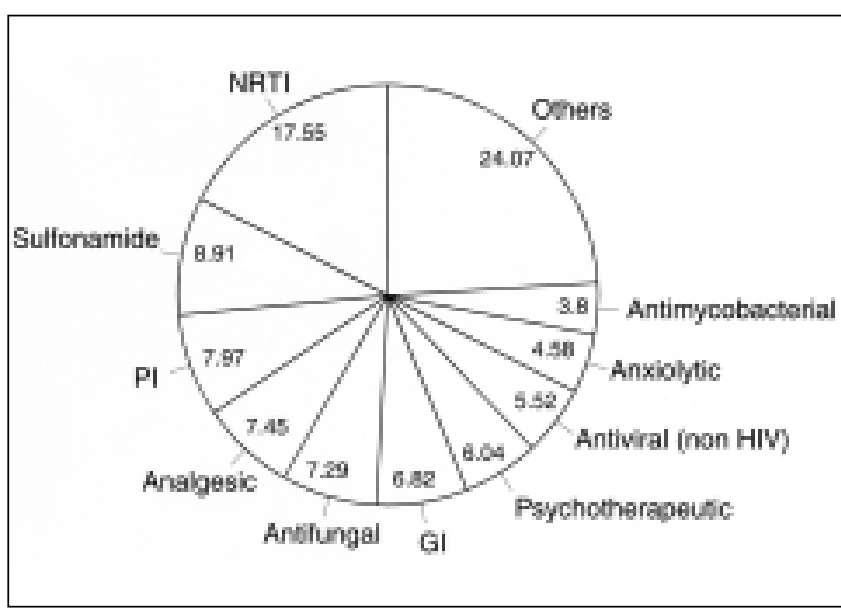

Figure 2) Drug classes taken after highly active antiretroviral therapy (phase 2). The percentage breakdown of medication classes is equal to the total number of drugs taken per class divided by the total number of drugs taken in all classes. GI Gastrointestinal; PI Protease inhibitor

CD4 counts were significantly higher and the number of concurrent illnesses was significantly lower than in phase 1 . The length of hospitalization did not differ between the two periods; however, there was a trend toward decreased duration of hospitalization in the post-HAART period. Likewise, there was no difference in the duration of admission between the two periods comparing the total number of admissions with ADRs $(\mathrm{n}=158)$ and those without ADRs $(\mathrm{n}=601)$ (9.94 versus 11.53 days, $\mathrm{P}=0.0964$ ).

Drug classes associated with ADRs: Figures 3 and 4 compare the breakdown of the top 10 drug classes associated with ADRrelated admissions in both phases. There was a significant shift in the drug classes associated with $\mathrm{ADRs}(\mathrm{P}=0.012)$, with the NRTIs, PIs and NNRTIs associated with more ADRs post-HAART, and the antiparasitic drugs (including pentamidine), psychotherapeutics and antineoplastics associated with more ADRs pre-HAART. Other drug classes involved in both phases were the sulphonamides, narcotic analgesics, other antivirals (ie, ganciclovir and foscarnet), antimycobacterials and antifungals.

ADR causality, severity, contribution to admission and outcomes: In summary, when combining both phases, over $80 \%$ of reactions were classified as possible or probable, over $60 \%$ were grade 3 or grade 4 in intensity, over $85 \%$ were either the main or contributing reason for the admission, and over $65 \%$ had at least partially recovered at the time of discharge. A more detailed account for each parameter is provided below.

Causality: The association of the drug with ADR in phases 1 and 2 , respectively, was classified as definite in $5.2 \%$ versus $12.4 \%$, probable in $41.4 \%$ versus $51.0 \%$, possible in $40.5 \%$ versus $29.9 \%$, conditional in $0 \%$ versus $1.0 \%$, doubtful in $12.9 \%$ versus $4.1 \%$, and unknown in $0 \%$ versus $1.0 \%(\mathrm{P}=0.011)$.

Severity: In phases 1 and 2, respectively, the intensity of the observed ADR was categorized as grade 1 (4.1\% versus $2.6 \%$ ), grade $2(33.0 \%$ versus $20.5 \%)$, grade 3 (21.7\% versus $34.6 \%$, grade $4(41.2 \%$ versus $41.0 \%)$ and unknown ( $0 \%$ versus $1.3 \%)$ $(\mathrm{P}=0.067)$.

Contribution to admission: In phases 1 and 2, respectively, the ADR was deemed as the main reason for admission in $42.3 \%$ versus $50.0 \%$ of cases, the contributing reason in $42.3 \%$ versus $46.2 \%$ of cases, unrelated in $14.4 \%$ versus $2.6 \%$ of cases, and unknown in $1.0 \%$ versus $1.3 \%$ of cases $(\mathrm{P}=0.025)$.

Outcome: The results for phases 1 and 2, respectively, are as follows: recovered (29.9\% versus $37.2 \%$ ), recovered with residual effects (38.1\% versus $43.6 \%$ ), not yet recovered ( $17.5 \%$ versus $12.8 \%$, fatal $(13.4 \%$ versus $5.1 \%)$ and unknown $(1.0 \%$ versus $1.3 \%)(\mathrm{P}=0.197)$.

Organ systems affected: The types and frequency of organ systems involved in ADRs did not differ between the phases (Figure 5). Because more than one system may have been involved in an ADR, the frequency of organ system involvement exceeds the number of ADRs reported. In phases 1 and 2, respectively, the most common toxicities seen involved the hematological system (32.7\% versus $26.8 \%$ ), the gastrointestinal tract ( $18.7 \%$ versus $24.1 \%)$, the central nervous system ( $9.4 \%$ versus $13.4 \%)$, dermatology (7.5\% versus $6.3 \%$ ), the hepatic system (7.5\% versus $3.6 \%$ ), and the renal system (6.5\% versus $4.5 \%$ ). Fatalities: In patients with ADRs on admission, there were 17 fatalities reported (14 in phase 1 , and three in phase 2). In phases 1 and 2, respectively, $8.9 \%$ ( 8 of 89 ) and 2.9\% (2 of 69) of ADRs were fatal. In phase 1 , six fatalities were not related to the ADR, four had a questionable relationship to the ADR and the remaining four were thought to be ADR-related. The drugs directly involved in these fatalities were foscarnet (severe renal failure); isoniazid, rifampin and pyrazinamide (hepatitis); trimipramine overdose (respiratory and metabolic alkalosis with rhabdomyalysis); and an experimental agent known as lithium gamma linolenic acid used in conjunction with co-

TABLE 2

Patient characteristics for admissions with adverse drug reactions of patients before and after the introduction of highly active antiretroviral therapy (HAART)

\begin{tabular}{lccc}
\hline & Phase 1 (pre-HAART) & Phase 2 (post-HAART) & P \\
\hline Number of admissions & $\mathrm{n}=89 / 436(20.4 \%)$ & $\mathrm{n}=69 / 323(21.4 \%)$ & 0.750 \\
Age (years) & $40.09 \pm 7.28$ & $38.99 \pm 7.81$ & 0.363 \\
Male (\%) & 94.4 & 95.7 & $1^{*}$ \\
CD4 count (cells $\left./ \mathrm{mm}^{3}\right)$ & $72.37 \pm 94.34(\mathrm{n}=84)^{\dagger}$ & $116.25 \pm 141.73(\mathrm{n}=64)^{+}$ & $0.0335^{\ddagger}$ \\
Number of concurrent diseases & $4.84 \pm 2.24$ & $3.87 \pm 2.24$ & $0.0074^{\ddagger}$ \\
Number of medications & $6.48 \pm 3.85$ & $6.61 \pm 4.49$ & 0.850 \\
Length of stay (days) & $11.24 \pm 10.32$ & $8.26 \pm 8.70$ & 0.0564 \\
\hline
\end{tabular}

${ }^{*}$ Fisher's exact test; ${ }^{\dagger}$ Data available; ${ }^{\ddagger} P<0.05$. HAART Highly active antiretroviral therapy 


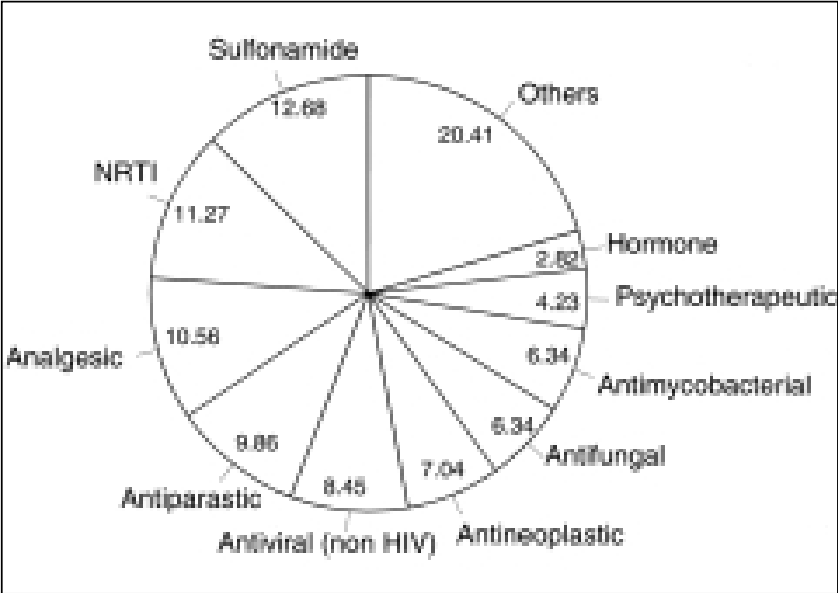

Figure 3) Drug classes associated with adverse drug reactions (ADRS) before highly active antiretroviral therapy (phase 1). The percentage breakdown of medication classes is equal to the total number of drugs per class causing ADRs divided by the total number of drugs in all classes causing ADRs. HIV Human immunodeficiency virus; NRTI Nucleoside reverse transcriptase inhibitor

trimxazole (hypersensitivity reaction causing interstitial nephritis and respiratory failure). Medications that may have contributed to the other mortalities were zidovudine and ganciclovir (neutropenia and death due to sepsis); amphotericin B (renal failure, acidosis and death due to pneumonia); pentamidine (renal failure, severe hypoglycemia, hyperkalemia and death due to aspiration pneumonia); bleomycin (pancytopenia, pulmonary toxicity and death due to query cytomegalovirus pneumonitis). In phase 2 , one death was not drugrelated. Dapsone-related hemolytic anemia contributed to one death (death due to splenectomy and pneumonia). Ritonavirinduced pancreatitis and hepatotoxicity (with dapsone/pyrimethamine-induced hemolytic anemia) were the probable causes of one death.

Antiretrovirals associated with ADRs: Table 3 lists the specific antiretrovirals and ADRs observed. Antiretrovirals contributed to ADR-related admissions in 21.3\% (19 of 89) and $36.2 \%$ (25 of 69) of cases in phases 1 and 2, respectively $(\mathrm{P}=0.038)$. This accounted for $4.4 \%$ (19 of 436$)$ and $7.7 \%$ ( 25 of $323)$ of all admissions $(\mathrm{P}=0.045)$. In phase 1 , the NRTIs were responsible for all antiretroviral-related admissions. In phases 1 and 2, respectively, zidovudine was associated with the most ADRs (15 versus 18 ), which were mainly anemia and neutropenia. Other NRTIs associated with ADRs were lamivudine (four versus six), didanosine (one versus two) and zalcitabine (four versus zero). In the majority of cases in both phases, antiretroviral ADRs were considered to be severe to very severe, were either the main or contributing reason for admission, and were possibly to probably linked to the antiretroviral agent. At the time of discharge, most patients had at least partially recovered from the ADR.

Post-HAART, $76 \%$ (19 of 25) of antiretroviral ADR-related admissions involved the NRTIs (27.5\% [19 of 69] of all ADRrelated admissions in phase 2 ). The PIs were associated with $24 \%$ ( 6 of 25 ) of antiretroviral ADR-related admissions $(8.7 \%$ [six of 69] of all ADR-related admissions). Indinavir was re-

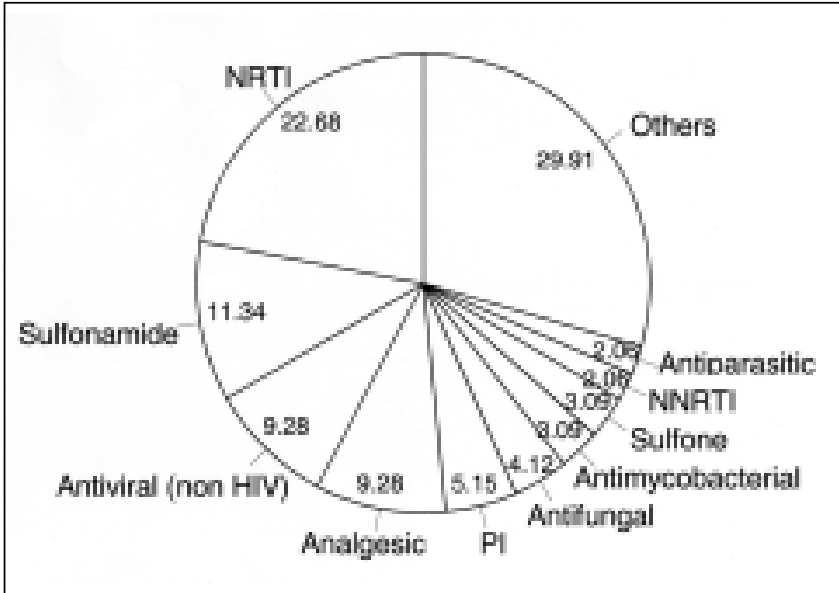

Figure 4) Drug classes associated with adverse drug reactions (ADRs) post-highly active antiretroviral therapy (Phase 2). The percentage breakdown of medication classes is equal to the total number of drugs per class causing ADRs divided by the total number of drugs in all classes causing ADRs. HIV Human immunodeficiency virus; NNRTI Non-nucleoside reverse transcriptase inhibitor; NRTI Nucleoside reverse transcriptase inhibitor; PI Protease inhibitor

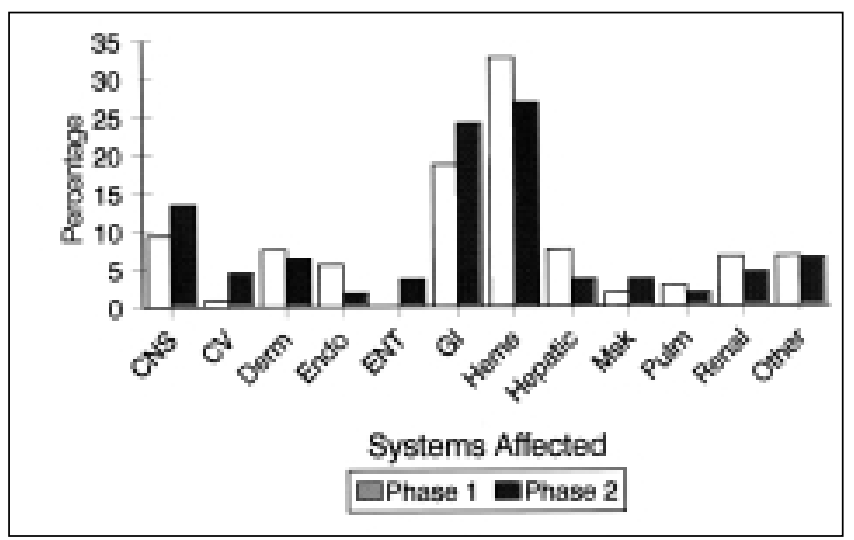

Figure 5) Organ system classification of adverse drug reactions. The percentage breakdown of organ system classification is equal to the frequency of specified organ system involved in adverse drug reactions divided by the total number of systems affected. CNS Central nervous system; CV Cardiovascular; Derm Dermatology; Endo Endocrine; ENT Ears, nose and throat; GI Gastrointestinal; Heme Hematological; Msk Musculoskeletal; Pulm Pulmonary

sponsible for $66.6 \%$ of all PI-related admissions, with the most common ADR being nephrolithiasis. Ritonavir was associated with fatal pancreatitis and liver failure in one patient, while saquinavir was suspected in a hypersensitivity reaction in another patient. The NNRTIs delavirdine and nevirapine each caused one admission due to severe hypersensitivity reactions, accounting for $8 \%$ (two of 25) of antiretroviral admissions and 2.9\% (two of 69) of all ADR-related admissions in phase 2.

Drug interactions: There were 12 drug-drug interactions noted on 11 admissions in phase 1 and seven interactions noted on seven admissions in phase 2 . These are summarized in Table 4 . Almost $75 \%$ of interactions were considered as potential interactions with serious consequences, but they did not result in detectable negative outcomes at the time of 
TABLE 3

Antiretrovirals associated with adverse drug events on admission of patients before and after the introduction of highly active antiretroviral therapy (HAART)

\begin{tabular}{|c|c|c|}
\hline Antiretroviral & Phase 1 ( $n=19$ admissions) & Phase 2 ( $n=25$ admissions) \\
\hline Nucleoside reverse transcriptase inhibitors & 19 admissions (100\%)* & 19 admissions $(76 \%)^{*}$ \\
\hline Zidovudine & $\begin{array}{c}12 \text { anemia } \pm \text { neutropenia } \\
1 \text { creatine kinase } \\
1 \text { liver enzymes } \\
1 \text { cardiomyopathy }\end{array}$ & $\begin{array}{l}14 \text { anemia } \pm \text { neutropenia } \\
2 \text { headache } \\
2 \text { nausea and vomiting }\end{array}$ \\
\hline Lamivudine & $\begin{array}{c}3 \text { anemia } \pm \text { neutropenia } \\
1 \text { nausea, vomiting and diarrhea }\end{array}$ & $\begin{array}{c}2 \text { anemia } \pm \text { neutropenia } \\
1 \text { headache } \\
1 \text { acute psychosis } \\
1 \text { neuropathy } \\
1 \text { nausea and vomiting }\end{array}$ \\
\hline Didanosine & 1 diarrhea and colonic distension & 2 neuropathy \\
\hline Zalcitabine & $\begin{array}{c}2 \text { neuopaty } \\
1 \text { pancreatitis } \\
1 \text { esophageal ulcers }\end{array}$ & - \\
\hline Protease inhibitors & - & 6 admissions $(24 \%)^{*}$ \\
\hline Indinavir & & $\begin{array}{c}3 \text { nephrolithiasis } \\
1 \text { nausea and vomiting }\end{array}$ \\
\hline Saquinavir & & $\begin{array}{c}1 \text { allergic reaction (also taking stavudine } \\
\text { and lamivudine) }\end{array}$ \\
\hline Ritonavir & & 1 pancreatitis (fatal) \\
\hline Non-nucleoside reverse transcriptase inhibitors & - & $\mathrm{n}=2$ admissions $(8 \%)^{*}$ \\
\hline Delavirdine & & 1 allergic reaction \\
\hline Nevirapine & & 1 allergic reaction \\
\hline
\end{tabular}

*More than one adverse drug reaction per admission caused by different antiretroviral classes were found in several admissions

TABLE 4

Drug interactions on admission

\begin{tabular}{|c|c|c|}
\hline Drug interaction description & Phase 1 ( $n=11$ admissions, 12 interactions) & Phase 2 ( $n=7$ admissions, 7 interactions) \\
\hline $\begin{array}{l}\text { Zidovudine + ganciclovir } \\
\text { Additive hematotoxicity }\end{array}$ & $\begin{array}{c}3 \text { anemia and neutropenia (Grade } 1 \text { to } 4)-1 \\
\text { fatality due to sepsis }\end{array}$ & - \\
\hline $\begin{array}{l}\text { Azole antifungal + cisapride } \\
\text { Contraindicated - cisapride AUC and potential } \\
\text { cardiotoxicity }\end{array}$ & 3 & - \\
\hline $\begin{array}{l}\text { Ketoconazole + gastric acid suppressant } \\
\text { Avoid ketoconazole efficacy }\end{array}$ & 4 (1 patient had evidence of thrush) & - \\
\hline $\begin{array}{l}\text { Saquinavir + rifabutin } \\
\quad \text { Contraindicated }-40 \% \quad \text { saquinavir AUC }\end{array}$ & 2 viral load unavailable & 2 viral load unavailable \\
\hline $\begin{array}{l}\text { Indinavir + rifabutin } \\
\qquad 300 \mathrm{mg} \mathrm{33 \%} \text { indinavir AUC and } 155 \% \text { rifabutin } \\
\text { AUC - decrease rifabutin to } 150 \mathrm{mg} / \text { day }\end{array}$ & - & 2 \\
\hline $\begin{array}{l}\text { Indinavir } 800 \mathrm{mg} \text { every } 8 \mathrm{~h}+\text { ketoconazole } \\
\qquad 68 \% \text { indinavir AUC - decrease indinavir dose to } \\
600 \mathrm{mg} \text { every } 8 \mathrm{~h}\end{array}$ & $\hat{u}$ & 1 \\
\hline $\begin{array}{l}\text { Ritonavir + diazepam } \\
\text { Contraindicated - diazepam AUC predicted }\end{array}$ & - & $\begin{array}{l}1 \text { acute confusion, paranoid delusions } \\
\text { and falls }\end{array}$ \\
\hline $\begin{array}{l}\text { Pseudoephedrine, dimenhydrinate, acetylsalicylic } \\
\text { acid and codeine, and haloperidol } \\
\text { Additive central nervous system side effects }\end{array}$ & - & $\begin{array}{l}1 \text { acute psychotic disorder due to } \\
\text { substance abuse }\end{array}$ \\
\hline
\end{tabular}

Data from references 7, 8, 14 and 15. AUC Area under the curve

evaluation. However, $25 \%$ (four of 12 ) and $28.6 \%$ (two of seven) of interactions in phases 1 and 2, respectively, were clinically evident on admission but did not affect the overall outcome at discharge. The most common interactions in phase 1 were combining an azole antifungal with cisapride or a gastric acid suppressant. The use of concomitant zidovudine and ganciclovir was associated with mild to very severe cytopenias in three patients (one fatality due to sepsis). Of note, in phase 1 , several patients were already taking saquinavir, a PI that was under study at the time. Two patients were treated concurrently with rifabutin, an agent known to decrease saquinavir levels by $40 \%$ (16). Viral load results were not available at that time to assess for virological failure.

In phase 2 , the PIs accounted for $85.7 \%$ of interactions. The most common interaction involved rifabutin and either indinavir or saquinavir. There were no cases of uveitis reported 
with the combined use of indinavir and full dose rifabutin. Indinavir was prescribed in full doses with ketoconazole; however, indinavir toxicity was not observed. The interaction of ritonavir with diazepam resulted in a significant interaction of grade 3 central nervous system toxicity from diazepam.

\section{DISCUSSION}

During the first year after the availability of HAART, HIV hospitalizations have decreased by 30\% at St Michael's Hospital, Wellesley Central Site. These findings are similar to trends observed in other HIV centres $(17,18)$. This decrease is likely multifactorial and may be attributed to more effective antiretroviral combinations, more aggressive outpatient management via homecare and the outpatient medical day unit, and an increased number of placement housing options for patients. Despite the decrease in hospitalizations at St Michael's Hospital, Wellesley Central Site, during this period, the mean number of medications taken, and the rates and duration of hospitalizations due to ADRs remained the same in the year preceding the introduction of HAART and the year after the introduction of HAART.

In a meta-analysis that examined ADR rates 49 hospitals from 1966 to 1989, the prevalence of ADR-related hospital admissions ranged from $0.2 \%$ to $21.7 \%(19)$. On average, $5 \%$ of hospital admissions were due to drug-related reasons, $4 \%$ of which were fatal. In contrast, the relatively high rate of hospitalization due to ADRs (20.9\% overall) found at St Michael's Hospital, Wellesley Central Site, is not unusual, given the recognized predisposition of HIV-infected persons to drug toxicities and hypersensitivity reactions in general (20). The higher ADR-related fatality rate ( $8.4 \%$ versus $2.6 \%$ ) common during pre-HAART period may be a function of the relatively advanced disease in this patient population, the use of more toxic drugs and the lack of HAART.

With the increased use of antiretrovirals post-HAART, a proportional increase in ADRs due to HAART agents was observed in our study. However, it is likely that this trend is even more pronounced today, given the widespread use of HAART, the use of 'mega-HAART' regimens such as salvage therapy $(21,22)$, double PI combinations (21-23) and the availability of even more antiretrovirals since the time of our study (eg, nelfinavir, saquinavir soft gel capsules, the NNRTIs [eg, efavirenz], abacavir and hydroxyurea). In addition, our data does not capture hospitalizations secondary to the long term toxicities of these agents, such as the PI lipodystrophy syndrome $(24,25)$. To our knowledge, we and others have subsequently seen admissions from nelfinavir (diarrhea and dehydration, hyperglycemic ketoacidosis, and rash requiring desensitization) (26-28); PIs in general (myocardial infarction linked to hyperlipidemias and hepatitis) (29-33); indinavir (interstitial nephritis and portal vein thrombosis) (34-36); abacavir (hypersensitivity reaction with intensive care admission) (37); efavirenz (depression with suicidal ideation) (38); and NNRTIs (rashes) (38).

Likewise, a higher incidence of hospitalizations secondary to drug interactions than that observed in our study is anticipated today, given the widespread use of HAART. For in- stance, we have seen acute ergotism due to the contraindicated combination of ergotamine and ritonavir, which has also been reported elsewhere (39). The inadvertent use of midazolam and the PIs in the intensive care unit has led to excess sedation in at least one patient. The combination of full dose rifabutin and the PIs has resulted in uveitis in another patient. Given the increased number of interaction studies that have been performed since the time of our study, and the heightened awareness of patients, pharmacists and other health care workers of serious interactions, these interactions and strategies for their management are expected to be identified and implemented more readily in the future.

In addition to ADR-induced morbidity and mortality, the impact that ADRs have on HAART adherence and subsequent drug resistance is significant. Several studies addressing risk factors for nonadherence have found that side effects and drug toxicities account for $11 \%$ to $35 \%$ of nonadherence to therapy (40-43). Piroth and colleagues (43) observed that 83 of 309 patients $(26.9 \%)$ in their cohort changed PI therapy due to adverse effects, with $65 \%$ of these changes occurring within the first two months of therapy. Treatment was discontinued in $26.7 \%$ of those on indinavir, $29.1 \%$ of those on ritonavir and $3.7 \%$ of patients on saquinavir. The main ADRs were gastrointestinal, urinary lithiasis (with indinavir), neurological effects and hepatitis (seen mainly with ritonavir and hepatitis $\mathrm{C}$ seropositivity) (43). Given the high prevalence of the lipodystrophy syndrome and the potential for nonadherence, preliminary reports of switching PI therapy for other agents with a different side effect profile (eg, the NNRTI class) are now emerging $(44,45)$.

Perhaps with closer monitoring in the community setting, these toxicities might be prevented and antiretroviral adherence may be improved. For instance, in the general population, Dartnell et al (46) found that $60 \%$ of ADR-related hospitalizations in a tertiary teaching hospital were possibly avoidable. They concluded that efforts to reduce ADRs must focus on counselling, education and monitoring of drug therapy (46).

\section{CONCLUSIONS}

In the one-year period immediately after the availability of the PIs, HAART had a significant impact on the incidence and nature of ADRs and interactions seen at St Michael's Hospital, Wellesley Central Site. Although the rates of hospitalization were similar pre- and post-HAART, a greater difference would now likely surface given the evidence of long term HAART toxicities and the widespread use of newer agents. Despite significant drug-induced morbidities in HIV patients, the survival benefits of HAART still outweigh the risks in most instances. Whether drug-induced mortality will further increase still remains to be determined. The overall impact of ADRs and interactions on antiretroviral adherence is significant and may further increase with long term use of HAART. It is our hope that through identification of ADRs and interactions, clinicians in ambulatory and inpatient settings will be alerted to the types of serious adverse effects and interactions that are seen in HIV patients, and may be better able to prevent, monitor and manage these reactions. 
ACKNOWLEDGEMENTS: The authors acknowledge the following sources of funding: Canadian Society of Hospital Pharmacists Research and Education Foundation, and Merck Frosst Canada, Dupont Pharma, Abbott Laboratories, Hoffmann LaRoche and Pharmacia Upjohn, Mississauga, Ontario.

\section{REFERENCES}

1. Hammer SM, Squires KE, Hughes MD, et al. A controlled trial of two nucleoside analogues plus indinavir in persons with human immunodeficiency virus infection and CD4 cell counts of 200 per cubic millimetre or less. AIDS Clinical Trials Group 320 Study Team. N Engl J Med 1997;337:725-33.

2. Palella FJ, Delaney KM, Moorman AC, et al. Declining morbidity and mortality among patients with advanced immunodeficiency virus infection. HIV Outpatient Study Investigators. N Engl J Med 1998;338:853-60

3. Hogg R, Yip B, Craib KJP, Schechter MT, O'Shaughnessy MV, Montaner JSG. Improved survival among men and women on triple antiretroviral therapy. 12th World AIDS Conference, Geneva, Switzerland, June 28 - July 3, 1998. (Abst)

4. Richman DD, Fischl MA, Grieco MH, et al. The toxicity of azidothymidine (AZT) in the treatment of patients with AIDS and AIDS-related complex. A double-blind, placebo-controlled trial. N Engl J Med 1987;317:192-7.

5. Bouvet E, Casalino E, Prevost MH, Vachon F. Fatal case of 2,3 dideoxyinosine-associated pancreatitis. Lancet 1990;336:1515. (Lett)

6. Daudon M, Estepa L, Viard JP, Joly D, Jungers P. Urinary stones in HIV-1 positive patients treated with indinavir. Lancet 1997;349:1294-5. (Lett)

7. Tseng AL, Foisy MM. Management of drug interactions in patients with HIV. Ann Pharmacother 1997;31:1040-58.

8. Tseng AL, Foisy MM. Significant interactions with new antiretrovirals and psychotropic drugs. Ann Pharmacother 1999;33:461-73.

9. Guill MF. Allergic drug reactions: identification and management. Hosp Formul 1991;26:582-4, 587-9.

10. Bergman U, Wiholm BE. Drug-related problems causing admission to a medical clinic. Eur J Clin Pharmacol 1981;20:193 200.

11. Grymonpre RE, Mitenko PA, Sitar DS, Aoki FY, Montgomery PR. Drug-associated hospital admissions in older medical patients. J Am Geriatr Soc 1988;36:1092-8.

12. Health Canada Report of adverse reaction suspected due to drugs, cosmetics, and biological products (vaccines excluded). Ottawa: Health Canada, 1995.

13. Toxicity severity grading scale (modified from the AIDS Clinical Trials Group). San Diego: Agouron Pharmaceuticals Inc, March 1997.

14. Tatro DS, ed. Drug Interaction Facts. St Louis: Facts and Comparisons Division, JB Lippincott Co, 1997.

15. Hansten PD, Horn JR, eds. Drug Interaction Analysis and Management. Vancouver: Applied Therapeutics, 1997.

16. Sahai J, Stewart F, Swick L, et al. Rifabutin reduces saquinavir plasma levels in HIV-infected patients. 36th Interscience Conference on Antimicrobial Agents and Chemotherapy, New Orleans, September 15-18, 1996. (Abst)

17. Cohn DL, Davidson AJ, Burman WJ, Coca VJ, Reves RR, Rietmeijer CA. Decreases in HIV-related morbidity, mortality, and health care utilization related to highly active antiretroviral therapy (HAART). 12th World AIDS Conference, Geneva, Switzerland, June 28 - July 3, 1998. (Abst)

18. Paul S, Ziecheck W, Gilbert HM, Jacobs J, Sepkowitz KA. Impact of HAART on rates and types of hospitalization at a New York city hospital. 5th Conference on Retroviruses and Opportunistic Infections, Chicago, February 1-5, 1998. (Abst)

19. Einarson TR. Drug-related hospital admissions. Ann Pharmacother 1993;27:832-40.

20. Bayard PJ, Berger TG, Jacobson MA. Drug hypersensitivity reactions and human immunodeficiency virus disease. J Acquir Immune Defic Syndr 1992;5:1237-57.

21. Montaner JSG, Jahnke N, Hogg R, et al. Multi-drug rescue therapy (MDRT) for HIV-infected individuals with prior virologic failure to multiple regimens: preliminary results. 38th
Interscience Conference on Antimicrobial Agents and Chemotherapy, San Diego, California, September 24-17, 1998. (Abst)

22. Youle M, Mocroft A, Johnson M, et al. Surrogate marker responses to multidrug combinations comprising hydroxyurea, efavirenz, double protease inhibitors and nucleoside analogues in protease inhibitor failures. 6th Conference on Retroviruses and Opportunistic Infections, Chicago, January 31 - February 4, 1999. (Abst)

23. Havlir DV, Lange JM. New antiretrovirals and new combinations. AIDS 1998;12(Suppl A):S165-74

24. Carr A, Samaras K, Burton S, et al. A syndrome of peripheral lipodystrophy, hyperlipidaemia and insulin resistance in patients receiving HIV protease inhibitors. AIDS 1998;12:F51-8.

25. Carr A, Samaras K, Chisholm DJ, Cooper DA. Pathogenesis of HIV-1protease inhibitor-associated peripheral lipodystrophy, hyperlipidaemia, and insulin resistance. Lancet 1998;351:1881-3.

26. Kosmyna JM, MacArthur RD. The incidence and severity of diarrhea in HIV+ patients from a large, urban medical center who have taken nelfinavir in the past twelve months. 12th World AIDS Conference, Geneva, Switzerland, June 28-July 3, 1998. (Abst)

27. Paterson DL, Singh N. Exacerbated hyperglycemia associated with nelfinavir. Ann Pharmacother 1998;32:609-10. (Lett)

28. Demoly P, Messaad D, Dohin P, Godard P, Bousquet J, Trylesinsky A. Nelfinavir-induced urticaria and successful desensitization. 12th World AIDS Conference, Geneva, Switzerland, June 28 to July 3, 1998. (Abst)

29. Henry K, Melroe H, Huebsch J, et al. Severe premature coronary artery disease with protease inhibitors. Lancet 1998;351:1328. (Lett)

30. SoRelle R. Vascular and lipid syndromes in selected HIV-infected patients. Circulation 1998;9:829-30.

31. Arribas JR, Ibanez C, Ruiz-Antoran B, et al. Acute hepatitis in HIV-infected patients during ritonavir treatment. AIDS 1998;12:1722-4. (Lett)

32. Rodriguez-Rosado R, Garcia-Samaniego J, Soriano V, Munoz F, Gonzalez-Lahoz J. Hepatotoxicity after introduction of highly active antiretroviral therapy (HAART). 12th World AIDS Conference, Geneva, Switzerland, June 28 - July 3, 1998. (Abst)

33. Orenstein R, Stewart M. Drug-induced hepatitis in the era of HAART. 38th Interscience Conference on Antimicrobial Agents and Chemotherapy, San Diego, California, September 24-17. 1998. (Abst)

34. Sarcletti M, Petter A, Zangerle R. Indinavir and interstitial nephritis. Ann Intern Med 1998;128:320-1. (Lett)

35. Marroni M, Gaburri M, Mecozzi F, Baldelli F. Acute interstitial nephritis secondary to the administration of indinavir. Ann Pharmacother 1998;32:843-4. (Lett)

36. Carr A, Brown D, Cooper DA. Portal vein thrombosis in patients receiving indinavir, an HIV protease inhibitor. AIDS 1997;11:1657-8. (Lett)

37. Hetherington S, Steel HM, Lafon S, Spreen W, Pearce G. Safety and tolerance of abacavir $(1592, \mathrm{ABC})$ alone and in combination therapy of HIV infection. 12th World AIDS Conference, Geneva, Switzerland, June 28 - July 3, 1998. (Abst)

38. Ruiz NM, Bessen LJ, Manion DJ, et al. Potential adverse experiences associated with efavirenz (EFV, SUSTIVA) in adults. 6th Conference on Retroviruses and Opportunistic Infections, Chicago, January 31- February 4, 1999. (Abst)

39. Caballero-Granado F, Viciana P, Cordero E, Gomez-Vera M, del Nozal M, Lopez-Cortes L. Ergotism related to concurrent administration of ergotamine tartrate and ritonavir in an AIDS patient. Antimicrob Agents Chemother 1997;41:1207. (Lett)

40. Beardsell A, Lai C, Hogg R, McLeod WA, Yip B. Utilization and adherence of a population-based post-exposure prophylaxis program. 6th Conference on Retroviruses and Opportunistic Infections, Chicago, January 31 - February 4, 1999. (Abst)

41. Wu A, Yu-Isenberg K, McGrath M, Jacobson D. Reliability, validity, and usefulness of touch-screen administration of QOL and adherence instruments in an outpatient clinic. 6th Conference on Retroviruses and Opportunistic Infections, Chicago, January 31 - February 4, 1999. (Abst)

42. Tuldra A, Ferrer MJ, Rodriguez C, Bayes R, Burger D, Clotet B. A proposed model to predict compliance with antiretroviral therapy. 38th Interscience Conference on Antimicrobial Agents 
and Chemotherapy, San Diego, California, September 24-27, 1998. (Abst)

43. Piroth L, Grappin M, Waldner A, et al. Discontinuation of antiprotease inhibitor therapy due to drug toxicity: study of a cohort of 309 patients. 38th Interscience Conference on Antimicrobial Agents and Chemotherapy, San Diego, California, September 24-27, 1998. (Abst)

44. Raffi F, Bonnet B, Ferre V, et al. Substitution of NNRTI for protease inhibitor in patients on combination therapy with undetectable plasma viral loads. 6th Conference on Retroviruses and Opportunistic Infections, Chicago, January 31 - February 4, 1999. (Abst)

45. Moyle G, Baldwin C, Dent N, Gazzard B. Management of indinavir-associated metabolic changes by substitution with efavirenz in virologically controlled HIV+ persons. 6th Conference on Retroviruses and Opportunistic Infections, Chicago, January 31 - February 4, 1999. (Abst)

46. Dartnell JG, Anderson RP, Chohan V, et al. Hospitalisation for adverse events related to drug therapy: incidence, avoidability and costs. Med J Aust 1996;164:659-62.

\section{BOOK REVIEWS}

\section{Zoonoses (1998). SR Palmer, Lord Soulsby and DIH Simpson, eds. Oxford University Press, Canadian Branch, Don Mills, Ontario. ISBN 0-19-262380-x; 948 pages; $\$ 406.00$}

Animals are important players in human infectious diseases, and zoonoses are in the vanguard of emerging infections - Lyme disease to hantavirus, hemorrhagic fevers and the swine-associated Hendra-like virus outbreak in Malaysia. While zoonoses encompass a wide range of diseases with multiple clinical and epidemiological features and, importantly, different approaches for control, the diseases are similar in that successful control efforts require joint veterinary and medical efforts. It is the veterinary side that is forgotten or underappreciated by clinicians. Zoonoses, then, is "aimed at developing the coordinated medical and veterinary approach to investigation and control". It is not all inclusive, and specifically claims that it "deals with the major zoonoses", and minor "occasional infections" in man have been excluded.

In 1959, the World Health Organiztion defined zoonoses as "diseases and infections which are naturally transmitted between vertebrate animals and man". This definition is somewhat muddied by the increasing frequency of opportunistic infections in highly immunocompromised patients. Further attempts to classify zoonoses have proposed the categories of 'direct zoonoses', with transmission by direct contact; 'cyclozoonoses', which require more than one species or vertebrate host; 'meta-zoonoses', which require transmission by an invertebrate vector in which the agent develops or multiplies; and "sapro-zoonoses", where both the vertebrate host and a nonanimal development site, or reservoir, are required. While such classifications highlight the means of transmission and then define approaches to control, their utility in clinical medicine is questionable.

Zoonoses is divided into three sections: bacterial, chlamydial and rickettsial zoonoses; viral zoonoses; and parasitic zoonoses. Infectious disease clinicians may find the order of the chapters within the three subgroups awkward, because it is alphabetically by disease name rather than by classification on the basis of species or Gram stain and morphology. "Mosquito-borne arboviruses", however, are under ' $M$ ' and "Diseases caused by corynebacteria and related organisms" is under ' $D$ '. Each chapter discusses history and background, the agent, animal and human hosts, epidemiology and transmission in animals and humans, and prevention and control.
Infectious disease clinicians do not need another text describing clinical aspects of infectious diseases, so the value of this book must rest on the additional information and insights provided on the animal perspective. From this view, the text is a useful and readable addition to the infectious diseases bibliography. Most chapters provide excellent indepth discussions of animal disease and control measures. We read about influenza in horses, salmonellosis in young calves, and giardiasis in dogs and cats. But there are a few disappointments. The chapter on brucellosis, for instance, provides complete discussion of infection in domestic animals, but there is no acknowledgement of the infection in nondomesticated animals such as caribou in northern Canada. The book is particularly useful for descriptions of less common parasitic diseases, which often receive relatively short commentary in infectious disease texts. Thus, blastocystis and diplyllobothrium receive extensive discussion, and Enchinococcus multlocularis has virtually a chapter of its own. Despite the claim that only major zoonoses will be discussed, there is a chapter for "foot and mouth disease, vesicular stomatitis, Newcastle disease, and swine vesicular disease". Infections of major importance in animals, but that very rarely cause disease in humans, it is argued that their significance in animals warrants inclusion.

For most chapters, the history and background sections, which describes animals as well as humans, are also complete and will be of interest to physicians who may not be aware of some of the animal history of these diseases. The discussion of approaches to controlling infectious agents, such as campylobacter and salmonella, in human food sources are particularly enlightening. The text is up to date, with full discussions of hantavirus, Marburg and Ebola viruses, cat scratch disease and prions.

This book, then, is timely and useful. For clinical infectious disease physicians, it is an excellent resource of the veterinary aspects of human disease. It is of general interest, or as a reference when searching for specific information relevant to clinical cases. One proviso, however, is that at the cost of $\$ 406$, it may not be necessary for everyone's library, but certainly should be accessible as a reference text.

Lindsay Nicolle MD FRCPC University of Manitoba Winnipeg, Manitoba 


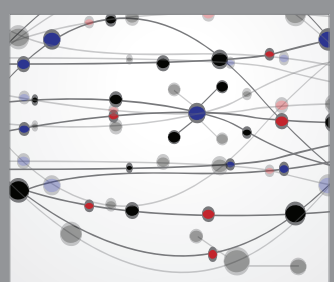

The Scientific World Journal
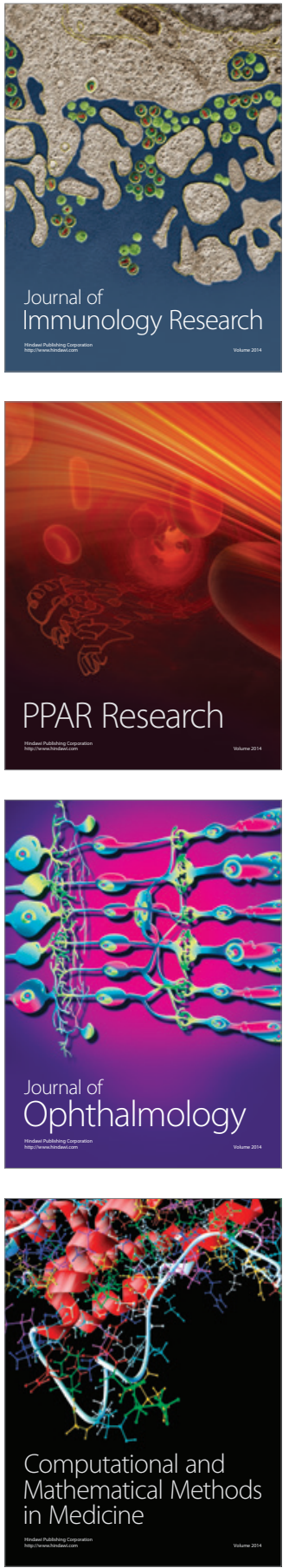

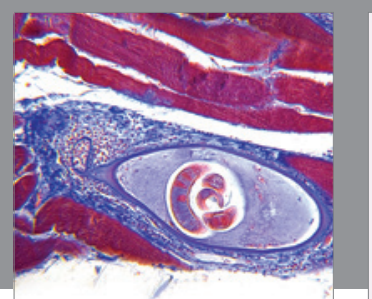

Gastroenterology Research and Practice

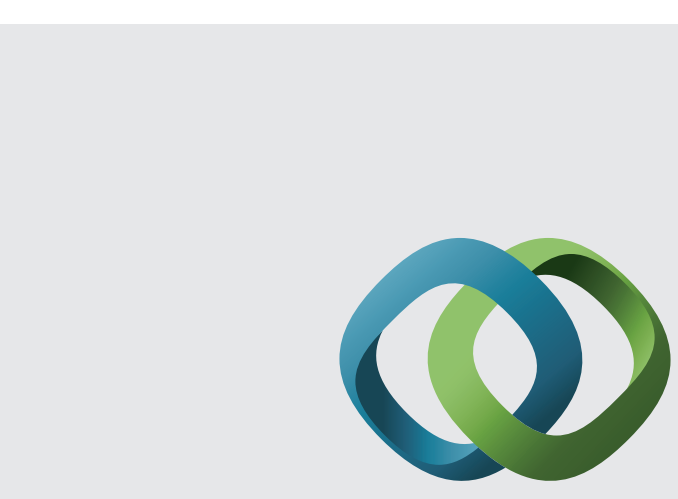

\section{Hindawi}

Submit your manuscripts at

http://www.hindawi.com
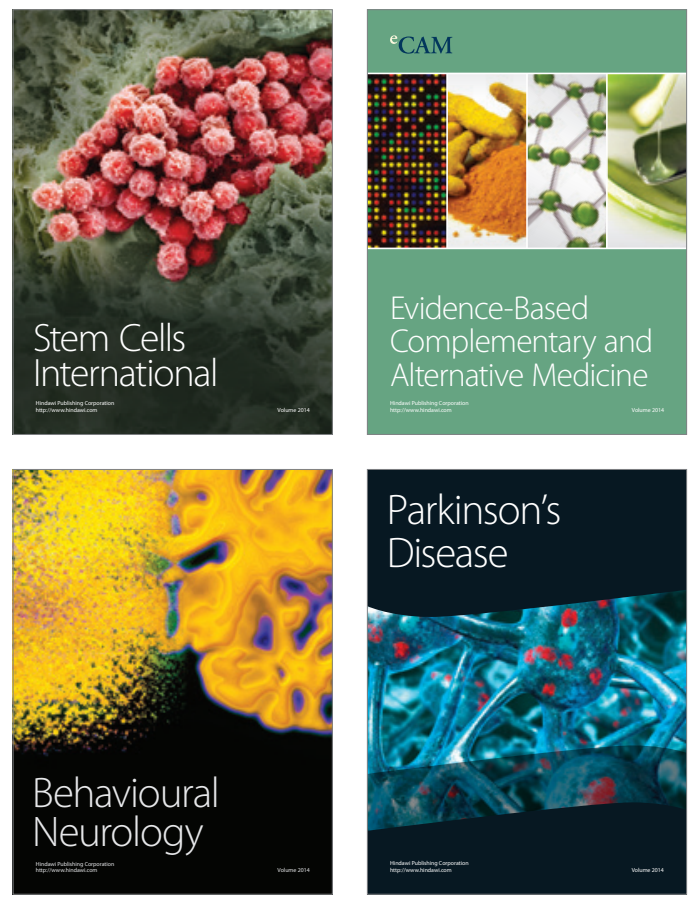
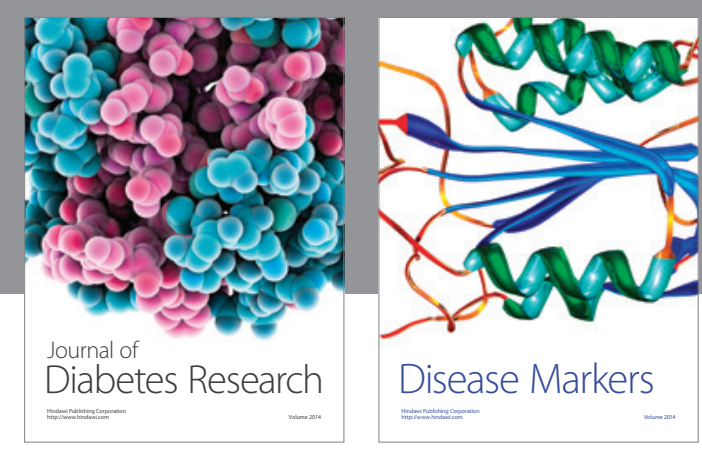

Disease Markers
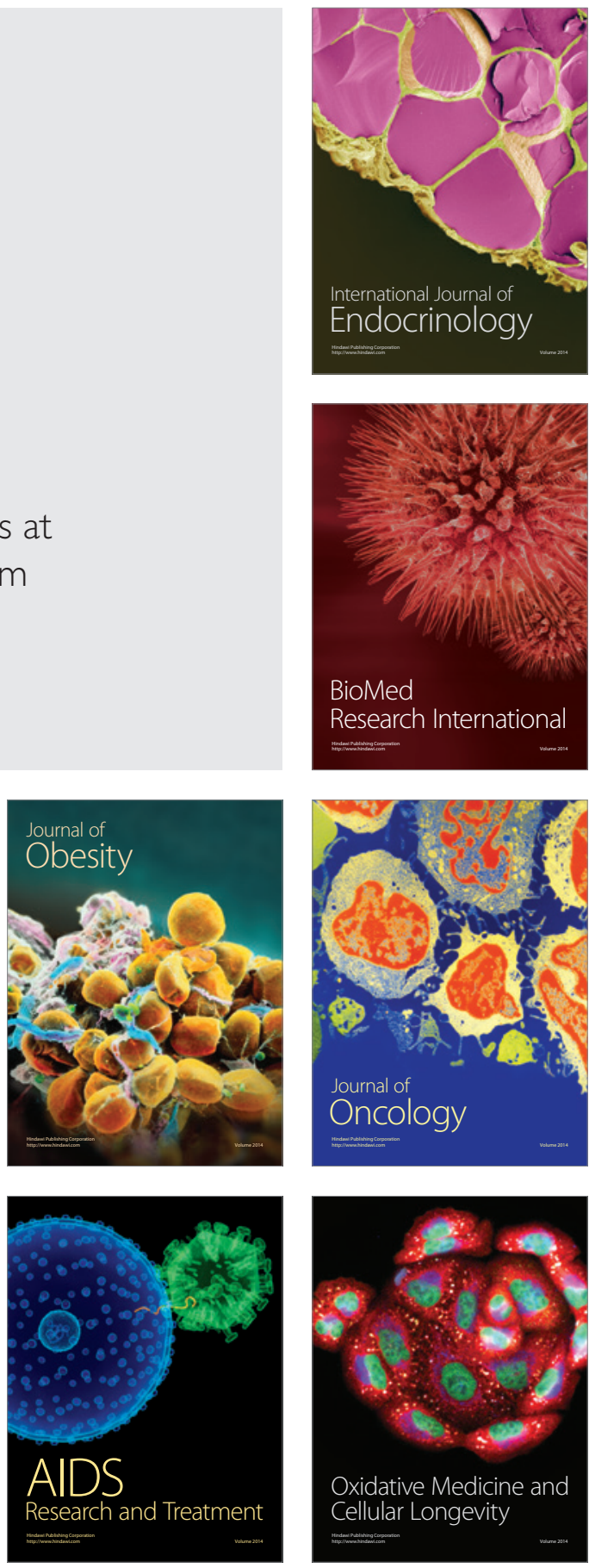